\title{
Kucsko-Stadlmayer: Europäische Ombudsmann-Institutionen.
}

\author{
598 S, Springer (Wien - New York 2008), Brosch. Euro 89,95,
} ISBN: 978-3-211-72840-6.

Das Buch ist das Ergebnis eines Forschungsprojekts über die rechtsvergleichende Analyse von Ombudsmännern. Der erste, von der Herausgeberin verfasste Teil ist der anspruchsvollen Aufgabe der Auswertung der 49 Länderberichte gewidmet. Der Rechtsvergleich erfolgt strukturiert nach verschiedenen Gesichtspunkten. Die Einrichtungen der Mitgliedstaaten des Europarates sowie der Bürgerbeauftragten der EU werden gegliedert nach verschiedenen Ordnungskriterien wie deren Organisation, Kontrollmandat oder Befugnissen gegenübergestellt, die in eine Einteilung nach verschiedenen Modellen mündet. Ergänzt wird der rechtsvergleichende Teil durch die Einzeldarstellungen über die Rechtslage in 49 verschiedenen Ländern im zweiten Teil der Arbeit. Abgerundet wird das Werk durch den dritten Teil, der Tabellen und Diagramme enthält, die eine schnelle Erfassung der staatlichen Unterschiede ermöglichen. Das Ziel des Forschungsprojekts, einen strukturierten rechtlichen Vergleich zwischen den einzelnen europäischen Ombudsmann-Institutionen herzustellen, wird treffsicher erreicht und dem interessierten Leser wird ein bereichernder Blick über zahlreiche Grenzen hinweg geboten. 